\title{
PROTOCOLO DE OLIVOS: ALTERAÇÕES NO SISTEMA DE SOLUÇÕES DE CONTROVÉRSIAS DO MERCOSUL E PERSPECTIVAS
}

\section{Eduardo Biacchi Gomes}

Mestre e Doutorando em Direito pela UFPR, Professor de Direito Constitucional Comparado e Políticas Econômicas da PUC/PR, Advogado, Professor de Relações Internacionais e de Direito Internacional da UNIBRASIL.

\begin{abstract}
SUMÁRIO: Introdução; 1 A importância do sistema de solução de controvérsia nos processos de integração; 2 Apontamentos sobre o sistema de solução de controvérsias no Mercosul; 3 O Protocolo de Olivos. Principais objetivos; Conclusões; Referências bibliográficas.
\end{abstract}

\section{INTRODUÇÃO}

Instigante é a temática sobre o sistema de solução de controvérsias que evolve os atores internacionais. ${ }^{1}$ Por um lado, somente esses, como sujeitos de Direito Internacional Público, é que possuem a devida legitimidade para litigar no foro internacional. Aliás, JORGE FONTOURA, ao analisar o sistema de solução de controvérsias da OMC, esclarece que a sistemática dessa organização destina-se somente às nações "em viés estrito de direito público: as empresas conflitam, mas só os Estados podem formalmente litigar". ${ }^{2}$

No contexto da formação dos blocos econômicos, os litígios entre os Estados, são dirimidos através dos mecanismos de solução de controvérsias previstos nos seus tratados constitutivos. Assim a OMC - Organização Mundial do Comércio - estabelece o sistema de "Panels" ou "Comitê de Especialistas", a União Européia, o Tribunal de Justiça das Comunidades Européias e o Mercosul, o procedimento arbitral, instituído pelo Protocolo de Brasília, 1991, e que está para ser reformulado com o Protocolo de Olivos, assinado em 18 de fevereiro de 2002.

O processo de integração do Mercosul vem evoluindo de acordo com a vontade política de seus integrantes. Ainda não se tem uma estrutura definitiva do bloco, nem tampouco um sistema de solução de controvérsias definido, pois ambos são provisórios. Como estabelece o Tratado de Assunção, 1991, o Mercosul deverá ter concebido a sua estrutura definitiva quando o bloco tiver consolidado a sua integração, com a liberalização dos quatro fatores de produção (bens, pessoas, serviços e capitais) e a conseqüente instituição de um Mercado Comum, proposição que parece incerta no 
contexto atual, em face das crises econômicas que os países do bloco vêm sofrendo nesses últimos anos.

No âmbito do sistema de soluções de controvérsias no Mercosul, muito se evoluiu com a assinatura do Protocolo de Olivos, posto que se passa de um mecanismo ad hoc de solução de divergências (no qual se utiliza a via arbitral) para um procedimento permanente, institucionalizado e com regras processuais mais claras, o que permitirá a formação de uma jurisprudência para a construção do bloco econômico.

A construção e a evolução de um bloco econômico somente pode ocorrer com a existência de instituições permanentes, que venham a dar respaldo ao processo de integração. Nesse processo, tem grande importância o sistema de solução de controvérsias a ser adotado, notadamente porque quanto mais aperfeiçoado, maiores serão os graus de integração de confiança repassados para a comunidade internacional.

Muito já se debateu sobre o Mercosul, principalmente em relação ao seu futuro em face das crises e divergências entre os seus sócios. Entretanto, há que se ter em mente que se deve acreditar no processo de integração, pois esse é uma das alternativas que os seus sócios possuem de buscar o crescimento, consoante propõe o preâmbulo do Tratado de Assunção.

O Protocolo de Olivos, que será enfocado neste texto, efetivamente demonstra a vontade política de os Estados-Partes continuarem no processo de integração, além de poder se constituir no seu "divisor de águas", posto que, a partir do momento que venha a entrar em vigor, o bloco poderá passar por novas transformações.

\section{A IMPORTÂNCIA DO SISTEMA DE SOLUÇÃO DE CONTROVÉRSIA NOS PROCESSOS DE INTEGRAÇÃO}

Uma das maiores dificuldades em um processo de integração é a adoção de políticas comuns, por parte dos seus sócios, que visem o desenvolvimento do bloco econômico. Isso ocorre porque, muitas vezes, existem interesses divergentes, quer econômicos, políticos, sociais, culturais, dentre outros que podem dificultar o processo. ${ }^{3}$

A existência de instituições permanentes e de um próprio tribunal permanente pode garantir o sucesso de um bloco econômico, notadamente devido à diminuição da interferência política nas decisões às quais passam a ser mais "institucionalizadas", isto é, tem um procedimento próprio a ser seguido, garantindo-lhes maior juridicidade e, conseqüentemente, maior segurança na construção do processo de integração. ${ }^{4}$

3 Vide por exemplo o caso do Mercosul que, decorridos mais de 10 (dez) anos da integração, muito já foi realizado. Entretanto, muito há que ser feito e as divergências e interesses dos Estados devem ser superadas.

4 MORAES, Henrique Choer. O Novo Sistema Jurisdicional do Mercosul - Um primeiro olhar sobre o Protocolo de Olivos. In: Revista de Direito Constitucional e Internacional. 
A adoção de um eficaz sistema de solução de controvérsias no Mercosul efetivamente contribuirá para o engrandecimento e o desenvolvimento do bloco econômico. Aliás, como tivemos a oportunidade de esclarecer, a adoção de um Tribunal Internacional Permanente, baseado em princípios de Direito Internacional Público e com jurisdição obrigatória para os Estados-Partes, está na vantagem de os litigantes conhecerem previamente a composição do tribunal e as regras a serem adotadas, garantindo uma maior independência na solução dos litígios e na formação de uma jurisprudência específica. ${ }^{5}$

A sujeição de um Estado à jurisdição de um tribunal internacional rompe com os paradigmas e os conceitos clássicos de soberania, principalmente no sentido de que o Estado, enquanto ente soberano, não se sujeita à jurisdição de qualquer outro Estado ou de Organizações Internacionais. Entretanto, há que se observar que nada de incomum reside nesse fato, posto que é o próprio Estado que, por um ato de soberania, aceita, através da assinatura de um Tratado, sujeitar-se à jurisdição de um tribunal internacional e em face dos princípios clássicos de Direito Internacional Público (pacta sunt servanda e reciprocidade) deverá cumprir as normas decorrentes do Tratado. ${ }^{6}$

Uma das características do Direito Internacional Público é a ausência de uma "autoridade central" capaz de coercitivamente impor sanções sobre os atores da sociedade internacional, diferentemente do Direito Comunitário, no qual as decisões podem ser coercitivamente impostas por parte dos órgãos da União Européia, em face dos princípios do primado da norma comunitária e da aplicabilidade direta. ${ }^{7}$

Aliás, a construção dos referidos princípios, que não estão previstos de forma direta nos tratados institucionais da União Européia, decorreu da jurisprudência, principalmente através dos julgados Costa/Enel, Simenthal e Van Gen em Loss, o que ressalta a importância do TJCE na evolução do Direito Comunitário Europeu.

Assim, torna-se salutar que o processo de integração tenha um eficiente sistema de solução de controvérsias e, quanto mais desenvolvido maior será o sucesso da integração e maior será a credibilidade perante a sociedade internacional, pois o bloco demonstrará a devida maturidade jurídica para solucionar as suas divergências, abandonando os critérios políticos e adotando os jurídicos para solucionar as questões, dentre os quais se destacam as negociações diretas, mecanismo clássico do Direito Internacional Público.

5 GOMES, Eduardo Biacchi. Blocos econômicos e soluções de controvérsias. Uma análise comparativa a partir da União Européia e Mercosul. Curitiba: Juruá, 2001, p. 247-248.

6 Assim ocorre com o Mercosul pois, quando os Estados firmaram o Protocolo de Brasília, reconheceram como obrigatória a sujeição à jurisdição internacional.

7 Através desses princípios reconhece-se que as normas comunitárias têm primazia sobre as normas nacionais, que aquelas têm aplicabilidade direta nos ordenamentos jurídicos nacionais, o que traduz o Direito Comunitário em um direito de subordinação. 
Ao contrário do que possa parecer, a existência de divergências no bloco econômico, desde que dirimidas, demonstra o seu grau de evolução, pois o bloco permanece em funcionamento.

\section{APONTAMENTOS SOBRE O SISTEMA DE SOLUÇÃO DE CONTROVÉRSIAS NO MERCOSUL}

O Mercosul surgiu com a assinatura do Tratado de Assunção, datado de 26 de março de 1991. Junto ao tratado foi estabelecido, no Anexo III, um regime de solução de controvérsias, posteriormente substituído pelo Protocolo de Brasília, assinado em 17 de dezembro de 1991.

O sistema de solução de controvérsias, definido pelo Protocolo de Brasília, pauta-se pela sua provisoriedade, eis que o sistema definitivo deveria ser estabelecido quando o Mercosul atingisse o modelo de mercado comum, o que deveria ocorrer até 31 de dezembro de $1994 .{ }^{8}$

Não atingida essa meta, o Protocolo de Ouro Preto, assinado em 17 de dezembro de 1994, veio a reformular, ainda que provisoriamente, a estrutura institucional do bloco econômico e o sistema de solução de controvérsias.

O procedimento previsto no Protocolo de Brasília, cuja aplicação é competência do GMC, é dividido em duas fases: uma diplomática, que se inicia com as negociações diretas entre as partes e, posteriormente, segue com a mediação do GMC; e uma arbitral, através da constituição do tribunal arbitral, o que somente ocorrerá se as partes não lograrem êxito na solução de suas controvérsias.

A fase diplomática estabelecida pelo Protocolo de Brasília pode ser assim esquematizada: ${ }^{9}$

a) surgindo uma controvérsia, os Estados-Partes deverão tentar resolver a questão mediante negociações diretas, do que prestarão informações ao GMC;

b) decorrido o prazo de quinze dias sem que haja solução para a controvérsia, haverá a intervenção do GMC, que atuará como mediador. Nessa oportunidade o GMC, após dar oportunidade às partes para que se manifestem sobre o objeto da controvérsia, poderá utilizar-se do assessoramento de peritos, que darão parecer com a finalidade de subsidiar a solução a ser proposta;

c) o GMC formulará recomendações aos Estados-Partes, as quais deverão ser aceitas por consenso entre os litigantes;

d) caso as partes não aceitem as recomendações do GMC, instaurar-se-á o procedimento arbitral, mediante prévia comunicação pelo Estado interessado.

8 Art. $2^{\circ}$ do Anexo III do Tratado de Assunção.

9 Protocolo de Brasília, arts. $2^{\circ}$ a $6^{\circ}$. 
O procedimento diplomático estabelecido no Protocolo de Brasília é pautado pela celeridade, pois não poderá estender-se por mais de trinta dias. Além disso, permite às partes a tentativa de solucionar, de forma direta ou com a intervenção do GMC, suas controvérsias, o que evita os naturais desgastes políticos provenientes das divergências comerciais entre os países, pois possibilita que eles, por consenso, adotem solução que atenda aos interesses em disputa, afastando eventuais efeitos negativos que adviriam de decisões proferidas por um tribunal permanente, o que poderia, de certa forma, dificultar um processo integracionista em que os Estados não aceitam abrir mão de seus interesses em prol do interesse comum, como é o caso do estágio atual do Mercosul.

Caso reste infrutífera a fase diplomática, qualquer parte poderá solicitar a instauração da arbitragem à Secretaria Administrativa do Mercosul, que deverá notificar a outra parte e os demais Estados e o GMC. Incumbirá à SAM encaminhar o procedimento arbitral, ${ }^{10}$ assim esquematizado: ${ }^{11}$

a) constituição de um tribunal ad hoc, composto por três árbitros, incumbindo a cada Estado-Parte litigante indicar um, ${ }^{12}$ no prazo de quinze dias, sendo o terceiro escolhido, não nacional, por comum acordo entre as partes ou, na sua impossibilidade, por sorteio de um árbitro numa lista de dezesseis, organizada pelo GMC;

b) escolhidos os árbitros, o tribunal fixará sua sede e seguirá as regras, observando o contraditório e a produção de provas;

c) instalado o tribunal arbitral, esse irá proferir sua decisão segundo as disposições do ordenamento jurídico do Mercosul e os princípios do Direito Internacional pertinentes à questão, podendo decidir, mediante autorização das partes, por eqüidade, no prazo de trinta dias. As decisões são tomadas por maioria;

d) as decisões são inapeláveis, devendo ser cumpridas de imediato ou no prazo fixado pelo tribunal, facultando-se aos litigantes, no prazo de quinze dias, solicitar esclarecimentos a respeito da decisão ou da forma como deverá ser cumprida;

e) as despesas são custeadas pelos Estados-Partes, em proporções iguais, e as decisões são lavradas nos idiomas espanhol e português.

O sistema estabelecido no Protocolo de Brasília é comumente utilizado na solução de controvérsias entre Estados soberanos e não traz nenhuma novidade no âmbito do Mercosul, mas reforça o entendimento dos governos de, ao menos nesta fase da

10 Protocolo de Brasília, art. $7^{\circ}$.

11 Protocolo de Brasília, arts. $9^{\circ}$ a 24.

12 Os árbitros são escolhidos mediante uma lista de dez nomes indicadas pelos Estados-Partes, que ficará registrada na Secretaria Administrativa do Mercosul. Obrigatoriamente a lista será composta por renomados juristas de reconhecida competência na matéria. Na hipótese de o Estado-Parte não indicar o árbitro, este será escolhido pela Secretaria Administrativa do Mercosul. 
integração, optar por mecanismos diplomáticos e da mediação para a solução dos conflitos, sem a necessidade de submeter as partes a uma corte permanente de justiça.

Já na arbitragem as partes podem, de certa forma, atuar na defesa de seus interesses, indicando os árbitros que irão compor o tribunal arbitral e sugerindo mecanismos e regras procedimentais para a solução da questão. Muito embora se reconheça que a eleição desses procedimentos incumbe ao tribunal arbitral, os Estados têm maior poder de atuação do que teria um tribunal permanente, no qual as regras são institucionalizadas.

Sobre o tema, ADRIANA NOEMI PUCCI leciona que o importante é salientar que os Estados-Partes do Mercosul têm apostado nos meios alternativos de soluções de conflitos, por terem entendido serem esses meios os caminhos que oferecem soluções mais rápidas e eficientes na solução de controvérsias que se suscitem pela aplicação ou interpretação, pelos Estados-Partes, da normativa Mercosul. [...] Espera-se que a utilização desses meios de solução de controvérsias contribua para o aprofundamento do processo de integração e que qualquer modificação ou reforma a ser feita nos procedimentos vigentes mantenha os princípios de celeridade e efetividade na solução de controvérsias, princípios necessários ao bom andamento das operações comerciais que se desenvolvem dentro do âmbito do Mercosul. ${ }^{13}$

O procedimento arbitral estabelecido no Protocolo de Brasília, como a maioria dos mecanismos jurisdicionais regulamentados pelos princípios do Direito Internacional Público, não garante o acesso do particular, de forma direta, à jurisdição internacional; podem eles, pessoas físicas ou jurídicas, utilizar-se dessa jurisdição por mecanismos indiretos. ${ }^{14}$

Uma vez que não são sujeitos, diretamente, dos direitos e obrigações decorrentes da assinatura de um tratado internacional, pois não são considerados sujeitos de Direito Internacional Público, os particulares só podem ter acesso à jurisdição internacional por vias indiretas, como é o caso previsto no art. 25 e seguintes do Protocolo de Brasília, abaixo analisado.

O procedimento a ser observado é o seguinte:

a) o particular formalizará uma reclamação com base no art. 25 do Protocolo de Brasília à Seção Nacional do Grupo do Mercado Comum onde tenha sua residência habitual ou a sede de seus negócios, fornecendo os elementos comprobatórios de sua reclamação;

b) recebida a reclamação, a Seção Nacional do GMC poderá estabelecer negociações diretas com a Seção Nacional do GMC do Estado parte

13 PUCCI, Adriana Noemi. Solução de controvérsias no Mercosul: mediação. In: OLIVEIRA, Angela (Coord). Métodos de resolução de controvérsias. São Paulo: LTr, 1999, p. 45-56.

14 Segundo esclarece REZEK, um dos requisitos para se qualificar os sujeitos de Direito Internacional Público é a sua capacidade de celebrar tratados e, portanto, estão sujeitos ao cumprimento dessas normas. Assim, consideram-se como sujeitos de Direito Internacional Público os Estados independentes, as organizações internacionais e a Santa Sé (Direito dos tratados, p. 25-26). 
demandado, visando uma solução imediata da questão, ou levá-la ao GMC para sua decisão. A questão também será levada à apreciação do GMC caso a Seção Nacional, no prazo de quinze dias, não lhe dê solução;

c) levada para a apreciação do GMC, esse, na primeira reunião subseqüente, avaliará a reclamação do particular, podendo denegar-lhe seguimento ou aceitá-la. Na segunda hipótese, convocará peritos para auxiliá-lo na solução da controvérsia e emitirá sua decisão no prazo de trinta dias;

d) se o reclamo do particular for considerado procedente pelo GMC, o EstadoParte reclamado poderá optar por acatar voluntariamente o parecer, oportunidade em que deverá tomar as medidas corretivas ou anular as medidas questionadas;

e) ou poderá rejeitar o parecer, hipótese em que qualquer dos Estados-Partes poderá acionar a via arbitral do Protocolo de Brasília.

Observe-se que, em verdade, ao particular somente é possibilitado apresentar um reclamo em âmbito administrativo e na Seção Nacional do GMC de sua residência ou da sede habitual de seus negócios, todavia sem efetiva participação nos procedimentos subseqüentes, pois a questão é levada à apreciação dos órgãos do Mercosul e dos próprios Estados envolvidos.

Também ao procedimento arbitral lhe é vedado acesso direto, pois, no caso de o Estado infrator se recusar a acatar o parecer do GMC, seu reclamo somente poderá ser apreciado pelo Tribunal Arbitral do Mercosul.

O sistema de acesso dos particulares previsto no Protocolo de Brasília não garante de forma efetiva a tutela dos seus direitos no âmbito do Mercosul e repete os mecanismos já previstos para solução de litígios internacionais, que facultam o acesso à jurisdição dos tribunais internacionais somente aos sujeitos de Direito Internacional Público.

Com vistas ao desenvolvimento do bloco econômico, os Estados-Partes buscaram aperfeiçoar o sistema de solução de controvérsias que, ainda provisório, pauta-se pelo seu caráter institucional, eis que fixado com regras e procedimentos próprios, o que permitirá a construção de uma jurisprudência da integração no Mercosul e contribuirá para o aprofundamento do bloco econômico.

\section{O PROTOCOLO DE OLIVOS. PRINCIPAIS OBJETIVOS}

O Protocolo de Olivos, assinado em 18 de fevereiro de 2002, entrará em vigor decorrido o prazo de 30 (trinta) dias a contar da data em que o último Estado-Parte ratificar o instrumento. A partir daí, ter-se-á a revogação do Protocolo de Brasília, entretanto, as controvérsias iniciadas no procedimento anterior deverão ser concluídas sob o sistema de solução de controvérsias anterior.

Cumpre observar que o sistema de solução de controvérsias estabelecido pelo Protocolo de Olivos é uma reformulação do sistema anterior e não se trata do sistema definitivo, que deverá ser adotado quando da culminação do processo de convergência da tarifa externa comum, a TEC. 
Tem como principais objetivos buscar a evolução do sistema de solução de controvérsias para que haja a correta interpretação e aplicação dos tratados fundacionais e normas originadas no bloco econômico, o desenvolvimento no processo de integração fundamental e a harmonização na aplicação e interpretação das normas oriundas do direito da integração. ${ }^{15}$

O objeto é a solução dos conflitos surgidos no bloco econômico ou em outros "esquemas preferenciais"16 ou junto à própria OMC - Organização Mundial do Comércio. Uma vez que os países elejam o sistema de solução de controvérsias, não poderão fazer se valer de outros mecanismos. Aliás, não foi oportuno para o desenvolvimento da integração a inserção dessa possibilidade, posto que as divergências advindas no bloco devem ser resolvidas pelo sistema nele estabelecido sem deixar transparecer as divergências para as demais economias extrabloco.

PEROTTI sobre o assunto menciona que esta prática é errônea pois contraria os objetivos do Tratado de Assunção. ${ }^{17}$

Entretanto, pelo determinado no Protocolo de Olivos surgida a controvérsia, quer decorrente de violação das normas do bloco econômico ou da $\mathrm{OMC}$, poderão os Estados eleger a via procedimental a ser adotada.

Outra grande inovação foi a institucionalização do procedimento, com a criação de regras mais claras, inclusive estabelecendo-se um Tribunal Permanente de Recursos, composto por 5 (cinco) membros com mandato de 2 (dois) anos, todos com disponibilidade permanente para o desempenho de suas funções.

Como na sistemática anterior, uma vez identificada a controvérsia, devem os Estados litigantes buscar solucionar o litígio através de negociações diretas no prazo de 15 (quinze) dias. Não havendo êxito, é facultada a intervenção do GMC que, dentro de 30 (trinta) dias, deverá emitir o seu pronunciamento.

Independentemente da intervenção do GMC, caso não haja a solução do litígio, qualquer Estado poderá solicitar a instauração do procedimento arbitral ad hoc. Os procedimentos, basicamente, não diferem do estabelecido no Protocolo de Brasília. A novidade é a possibilidade da unificação da representação, na hipótese de que dois ou mais Estados venham a sustentar a mesma posição na controvérsia, quando poderão designar um mesmo árbitro e na impossibilidade de, uma vez definido o objeto da controvérsia, o mesmo ser alterado durante o procedimento.

15 Aliás, cumpre asseverar que no Mercosul não há que se falar no princípio de uniformidade na aplicação e interpretação do Direito da integração ante à inexistência do Direito Comunitário e da supranacionalidade. Assim os Estados-Partes devem buscar pelos mecanismos do Direito Internacional Público e das instituições intergovernamentais a devida harmonização das normas produzidas no bloco.

16 Art. $1^{\circ}$ do Protocolo de Olivos, entendidos como acordos comerciais assinados entre os países.

17 PEROTTI, Alejandro Daniel. Qué significó el Protocolo de Olivos. Fue un paso adelante, con reservas. 
Também foi estabelecido, de forma mais clara, a possibilidade da adoção de medidas provisórias, tendo o Tribunal a competência de, a qualquer momento, definir as medidas a serem adotadas para prevenir eventuais danos, bem como sustar as medidas.

Emitido o laudo, que é obrigatório, o mesmo poderá ser objeto de revisão pelo Tribunal Permanente de Revisão, devendo a parte que se julgar prejudicada interpor o recurso no prazo de 15 (quinze) dias.

O Tribunal será composto por 5 (cinco) árbitros, sendo que cada Estado indicará um membro e seu suplente para um mandato de 2 (dois) anos, renovável por dois períodos consecutivos. O quinto será indicado de comum acordo entre os Estados para um mandato de 3 (três) anos, não renovável. Na hipótese de não haver unanimidade na designação do quinto árbitro, esse será designado por sorteio a ser realizado pela Secretaria Administrativa do Mercosul através de uma lista de árbitros fornecida pelos Estados-Partes.

Se o litígio envolver dois Estados, o Tribunal será composto por 3 (três) árbitros e, na hipótese de envolver mais de dois Estados, será composto por 5 (cinco) árbitros. Em qualquer hipótese o presidente não poderá ter a nacionalidade dos Estados envolvidos na controvérsia.

O Protocolo de Olivos faculta às partes a possibilidade do acesso direto ao Tribunal de Revisão, hipótese na qual os laudos emitidos serão obrigatórios e sem a possibilidade de revisão.

São estabelecidos, de forma clara, as garantias do cumprimento do laudo arbitral, como por exemplo a possibilidade de a parte inadimplente ser obrigada a cumprir medidas compensatórias, as quais não a eximem das determinações estabelecidas no laudo arbitral.

Nesse sentido, o Tribunal poderá intervir, desde que instado, em qualquer fase com vistas a determinar a aplicação de medidas compensatórias, bem como suspendêlas. $^{18}$

Dentre as competências do Tribunal Permanente de Recursos e do Tribunal ad hoc está a possibilidade de conhecer do Recurso de Esclarecimento que deverá ser interposto no prazo de 15 (quinze) dias, contar de sua manifestação.

O Protocolo de Olivos não trouxe novidades em relação ao acesso dos particulares no sistema de solução de controvérsias, pois como no procedimento anterior não podem ter acesso direto, eis que não são sujeitos de direito internacional.

18 A aplicação de medidas compensatórias, segundo o disposto no art. 31 do Protocolo de Olivos, é uma faculdade que o Estado vencedor poderá requerer ao Tribunal a sua aplicação caso no outro Estado não venha a cumprir o laudo decorrido o prazo de até um ano da sua emissão, como por exemplo a suspensão de concessões ou de outras obrigações equivalentes. Inicialmente deverá buscar a suspensão das concessões ou obrigações equivalentes no mesmo setor objeto da controvérsia. Caso reste infrutífera, poderá aplicar em outros setores, desde que fundamente a sua aplicação. Caso o outro Estado se julgue prejudicado, poderá questionar, perante o Tribunal, a adoção das medidas. 
Com o aperfeiçoamento do sistema de solução de controvérsias, espera-se um maior desenvolvimento da integração. Sem dúvida, o estabelecimento de procedimentos e regras mais claras contribuirão para o sucesso do sistema e na convergência dos interesses dos Estados-Partes. A adoção do Protocolo de Olivos, ainda que provisória, mostra a vontade dos parceiros do bloco em continuar com o processo de integração e os seus objetivos.

\section{CONCLUSÕES}

O Mercosul, enquanto processo de integração, vive um momento de incertezas. A existência de um mecanismo de solução de controvérsias, ainda que provisório, entretanto mais desenvolvido que o anterior, demonstra a vontade política de os Estados continuarem no processo de integração.

Para que o Mercosul venha a desenvolver-se enquanto bloco econômico, necessária é a existência de órgãos de caráter permanente e com regras e procedimentos institucionalizados. Com a assinatura do Protocolo de Olivos, muito se avançou nesse aspecto, pois quando o Tratado entrar em vigor será possível a formação de uma verdadeira jurisprudência no processo de integração. ${ }^{19}$

No aspecto interno (intrabloco), a adoção de um sistema de solução de controvérsias institucionalizado é de vital importância para o sucesso da integração, pois a partir daí podem ser criadas outras soluções, diferentes das previstas nos tratados fundacionais que venham a solucionar eventuais divergências no âmbito do bloco econômico, a exemplo da União Européia.

No aspecto externo, a existência de um eficaz mecanismo de solução de controvérsias demonstra aos demais países e para a própria sociedade internacional o sucesso em um processo de integração e a possibilidade que os parceiros possuem em solucionar suas divergências, o que de certa forma pode atrair investimentos para os países.

Enfim, o próprio sucesso do Mercosul depende, efetivamente, da vontade política de seus parceiros em continuar neste ambicioso e arrojado projeto de integração, bem como na entrada em vigor desse novo sistema de solução de controvérsias que, sem dúvidas, será de grande importância para a sua continuidade e sucesso.

A assinatura do Protocolo de Olivos, pendente de ratificação por parte dos Estados, demonstra a maturidade política dos parceiros em avançar no processo de integração, aprofundando-a em busca de novas alternativas, em face da globalização e do próprio sucesso da ousada proposta estabelecida inicialmente através do Tratado de Assunção. 


\section{REFERÊNCIAS BIBLIOGRÁFICAS}

FONTOURA, Jorge. A importância da OMC para o Brasil. Jornal Gazeta do Povo, 12 jul. 2002.

GOMES, Eduardo Biacchi. Blocos econômicos e soluções de controvérsias. Uma análise comparativa a partir da União Européia e Mercosul. Curitiba: Juruá, 2001, p. 247-248.

MORAES, Henrique Choer. O Novo Sistema Jurisdicional do Mercosul - Um primeiro olhar sobre o Protocolo de Olivos. In: Revista de Direito Constitucional e Internacional.

PEROTTI, Alejandro Daniel. Qué significó el Protocolo de Olivos. Fue un paso adelante, con reservas. La Nación Line de 26.02.2002. Buenos Aires, Argentina.

PUCCI, Adriana Noemi. Solução de controvérsias no Mercosul: mediação. In: OLIVEIRA, Angela (Coord.). Métodos de resolução de controvérsias. São Paulo: LTr, 1999, p. 45-56. 